\title{
Hepato- Biliary Ascariasis- Experience from a Tertiary Care Hospital in North East India
}

\author{
${ }^{1}$ Ranendra Hajong, ${ }^{1}$ Dathiadam Tongper, ${ }^{1}$ Peter Daniel S Khariong, \\ ${ }^{1}$ Naloh Mibang \\ ${ }^{1}$ Department of General, NEIGRIHMS, Shillong, Meghalaya, India
}

\begin{abstract}
Background: Hepatobiliary ascariasis is commonly reported from highly endemic regions like India, Bangladesh, Latin America, parts of Middle East and Africa. In humans, the usual habitat of Ascaris lumbricoides is the small intestine. When the worm load is high, then the worms tend to migrate away from the usual site and invade the biliary system.
\end{abstract}

Material \& Methods: Patients attending general surgery department of NEIGRIHMS hospital with biliary ascariasis and its complications were included in the study.

Results: Most cases of biliary ascariasis can be managed conservatively. The worm usually returns to the intestine and only in complicated cases, some therapeutic interventions like ERCP or surgical management may be required.

Conclusion: Biliary ascariasis may present with biliary colic or with various complications like cholangitis, acute pancreatitis, liver abscess, etc. Sonography has been shown to have a high diagnostic accuracy in the diagnosis of biliary ascariasis. Most of the patients can usually be managed conservatively, and surgery or $E R C P$ are required only in a very limited number of cases.

Keywords: Ascariasis, hepatobiliary.

\section{Introduction:}

Ascariasis is mostly seen in tropical and subtropical countries, partly owing to the warm and humid conditions of the soil that is conducive to the development of the ascaris larvae, and partly due to the poor sanitary and hygienic conditions that help in maintaining the infection cycle (1). Ascaris lumbricoides , a nematode is the causative agent of ascariasis. It infects $25 \%$ of the world's population (2). In the Indian subcontinent, ascariasis is highly endemic in Kashmir (70\%), Bangladesh (82\%), Central and Southwest India $(20 \%$ to $49 \%)$ [3].

Normally the adult worms inhabit the intestinal lumen, mostly the jejunum without causing any symptoms. But when aggregated into masses, the worms may produce intestinal obstruction, volvolus or intussusceptions; rarely the worms migrate into bile duct. Ascarids have a great propensity to explore small openings (3). When in the duodenum, they may enter the ampullary orifice and advance into the bile and hepatic ducts, ultimately causing biliary ascariasis. Migration of the worms into the bile duct is often noticed after cholecystectomy, sphincterotomy, choledochostomy or sphincteroplasty $(3,4,5)$. It has been observed that cholecystectomy is followed by a rise in cholecystokinin, which together with secretin leads to relaxation of the sphincter of Oddi, thus opening the way for migration of worms (5). Biliary ascariasis is more commonly seen in women than in men (female to male ratio of 3:1) with the mean age of occurrence being 35 years (range:4-70 years) [3]. Pregnant women are more prone to develop biliary ascariasis, likely because of high levels of hormones like progesterone and estrogen (6).

All the patients included in this study presented in the emergency with acute upper abdominal colicky pain. In endemic areas, biliary ascariasis is a frequent diagnosis and should be kept in mind as a cause of upper abdominal pain.

\section{Materials and Methods:}

A total of 47 patients ( 36 females and 11 males) with biliary ascariasis were studied over a period of 3 years in the North Eastern Regional Institute of Health and Medical Sciences, Shillong, Meghalaya, India. All patients presented with acute upper abdominal pain. The patients' age ranged from 8 years to 67 years belonging to various parts of Meghalaya. Age distribution of patients is shown in table 1. 5 patients were pregnant, 2 of who were in their first trimester. Clinical assessment was performed in all the patients. History of passage of worms in the stool or vomitus, recurrent abdominal pain with or without jaundice, was taken from all the patients. Previous history of surgery or endoscopy to the gastrointestinal tract was noted. Complete blood count, liver function tests, serum amylase and lipase, chest $\mathrm{x}$-ray and abdominal $\mathrm{x}$-ray with ultrasonography of the 
whole abdomen were done in all the patients and repeated as and when required. CT scan or MRCP was not done in any patient, and ultrasonography of abdomen was the mainstay of diagnosis.

The ultrasonography pictures of various patients are shown as follows: Figure 1 showing round worm in the gall bladder; Figure 2 showing round worm in common bile duct and Figure 3 showing intrahepatic worms.

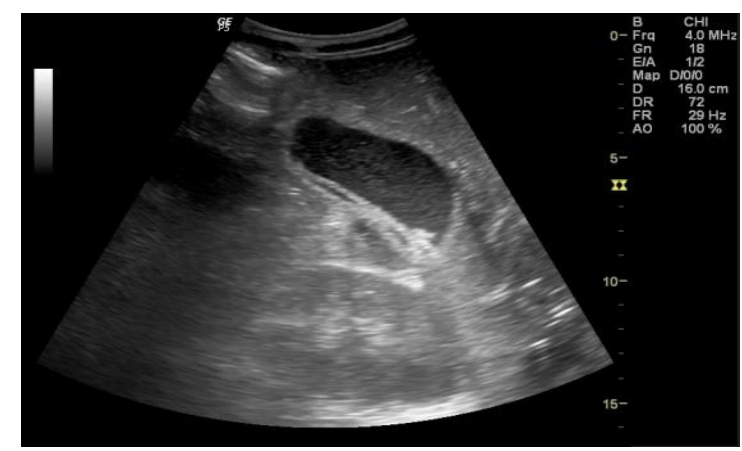

Figure 1 showing round worm in gall bladder

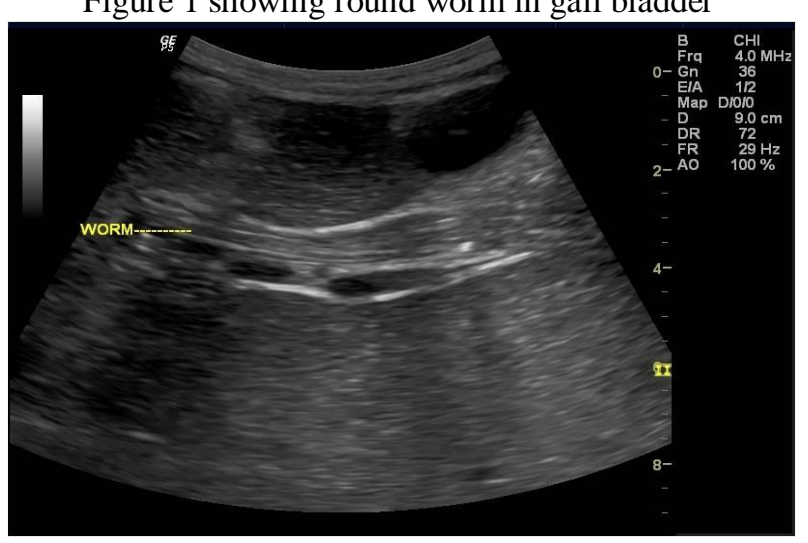

Figure 2 showing round worm in common bile duct

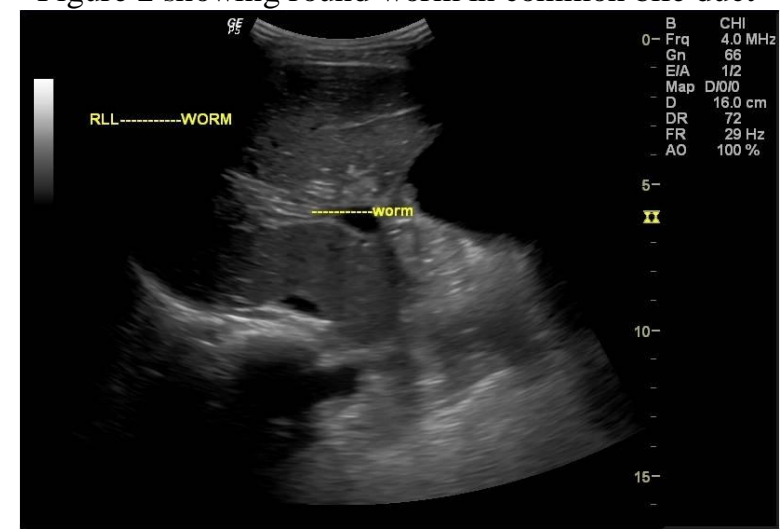

Figure 3 showing round worm in right lobe of liver.

All the patients were initially managed conservatively with IV fluids, IV antibiotics and IV antispasmodics. All the patients were dewormed with a single dose of $400 \mathrm{mg}$ albendazole except pregnant women in their first trimester. Pregnant women in their first trimester were not given any antihelminthic and were managed with IV antispasmodics only. Endoscopic or surgical intervention was carried out when conservative treatment failed. Serial ultrasonography was performed to check for recurrence during follow- up. The patients were dewormed at 6- monthly interval.

\section{Results:}

In this study, biliary ascariasis was found to be more common in females (76.60\%). The most common presenting symptom was upper abdomen pain $(95.74 \%)$ which was colicky in nature. The clinical signs and symptoms of the patients are given in Table 2. Worms were extracted from Ryle's tube in 3 out of 28 patients on Ryle's tube. The white blood cell count was moderately raised in 29 (61.70\%) with eosinophilia being predominant in most of the patients. Serum amylase and lipase were raised in 3 patients who had pancreatitis. 
Alkaline phosphatase was raised in $21(44.68 \%)$ patients. Intrahepatic lithiasis was found in 3 patients. Ascaris was found in the gall bladder in 1 patient.

Twelve patients had history of previous surgery of gastrointestinal tract, like cholecystectomy, choledochduodenostomy, endoscopic sphincterotomy, gastro-jejunostomy, etc.

Complications occurred in 27 patients namely Obstructive jaundice, Cholangitis, Acute Pancreatitis, Acute Cholecystitis, etc. (Table 3).85.11\% of patients responded to conservative management. Most of the patients responded to conservative treatment usually within 3 to 4 days of starting the treatment. Some patients were continued conservative management for as long as 7 to 8 days if the patient's general condition was stable and improving. ERCP was done with removal of worms from bile duct and pancreatic duct in 3 patients. Cholecystectomy was done in the patient presenting with gall bladder ascariasis. Common bile duct exploration was done in one patient. Choledochoduodenostomy was done in 1 patient with intrahepatic lithiasis which could not be retrieved, after common bile duct exploration.

Patients were followed- up for 6 months to 1 year time with serial ultrasonography. Worm reinvasion of the biliary tree was found in $2(4.26 \%)$ patients, who were managed conservatively.

\section{Age distribution:}

\begin{tabular}{|l|l|l|l|}
\hline Age range & $\begin{array}{l}\text { No of male } \\
\text { patients }\end{array}$ & $\begin{array}{l}\text { No of female } \\
\text { patients }\end{array}$ & $\begin{array}{l}\text { Total no of } \\
\text { patients }\end{array}$ \\
\hline$<10$ & 1 & 1 & 2 \\
\hline $10-20$ & 2 & 6 & 8 \\
\hline $21-30$ & 4 & 9 & 13 \\
\hline $31-40$ & 1 & 8 & 9 \\
\hline $41-50$ & & 8 & 8 \\
\hline $51-60$ & 3 & 3 & 6 \\
\hline $61-70$ & & 1 & 1 \\
\hline
\end{tabular}

Table 2: Clinical presentations

\begin{tabular}{|l|l|l|}
\hline Symptoms/signs & $\begin{array}{l}\text { No of } \\
\text { patients= 47 }\end{array}$ & Percentage \\
\hline Pain right upper quadrant of abdomen & 45 & 95.74 \\
\hline Biliary colic & 28 & 59.57 \\
\hline Nausea and vomiting & 36 & 76.60 \\
\hline Vomiting of worms & 14 & 29.79 \\
\hline Worms in Ryle's tube & $\begin{aligned} \text { 3 (out of 28 } \\
\text { patients) }\end{aligned}$ & \begin{tabular}{l}
10.71 \\
\hline
\end{tabular} \\
\hline Worms in stool & 27 & 57.45 \\
\hline Fever & 9 & 19.15 \\
\hline Right upper quadrant tenderness & 31 & 65.96 \\
\hline Jaundice & 15 & 31.91 \\
\hline Hepatomegaly (tender) & 6 & 12.77 \\
\hline Palpable GB lump & 4 & 8.51 \\
\hline
\end{tabular}

Table 3: Complications:

\begin{tabular}{|l|l|l|}
\hline Complications & No of patients $=27$ & Percentage \\
\hline Obstructive jaundice & 14 & 29.79 \\
\hline Cholangitis & 9 & 19.15 \\
\hline Acute Pancreatitis & 3 & 6.38 \\
\hline Acute Cholecystitis & 1 & 2.13 \\
\hline
\end{tabular}

\section{Discussion:}

Symptoms of biliary colic occur when the worm migrates across the papilla. If the worm remains in the bile duct and gall bladder, acute and chronic complications can occur like cholangitis, strictures, calculi, cholecystitis and pancreatitis (7). After entering the bile duct, the ascarids excrete various types of polypeptides that produce allergic manifestations and cause spasm of the sphincter of Oddi by acting as chemical irritants. 
The resultant biliary stasis coupled with infected intestinal contents carried by the worms leads to pyogenic cholangitis, cholecystitis and pancreatitis (8-10).

Biliary obstruction lasts only as long as a live worm remains in situ; the majority of worms retreat into the duodenum. Chang and Han (11) suggest several mechanisms of worm extrication:

i. Spasm of the ductal sphincter may cause vigorous movements of the un-trapped body and tail of the worm, which may force it to retract its head;

ii. Flushing of the bile duct promoted by antispasmodics and gall bladder contractions may eject the worm from the duct; or

iii. The worm may turn its head backwards and come out of the bile duct effortlessly.

The diagnosis of biliary ascariasis usually depends on the demonstration of worms in the biliary tract by different imaging techniques. Sonography has been shown to have a high diagnostic accuracy as a non-invasive procedure in the diagnosis of biliary ascariasis (12). Various appearances of round worms in the biliary tract and gall bladder have been described $(12,13)$. They are as follows:

1. Inner tube sign- The round worm may be seen as a thick echogenic stripe with a central anechoic tube (gastrointestinal tract of the worms) in the gall bladder or common bile duct.

2. Stripe sign- Thin nonshadowing stripe without an inner tube within gall bladder or common bile duct.

3. Spaghettli sign- Overlapping longitudinal interfaces in the main bile duct due to coiling of a single worm or several worms in the common bile duct.

Various approaches are available for dealing with biliary ascariasis, namely conservative management, endoscopic extraction and surgical intervention. More than $95 \%$ of the patients with uncomplicated biliary ascariasis will respond to conservative management, the worms returning spontaneously to the intestine $(7,14)$. Conservative treatment is usually continued for 72 hours; its progress assessed by clinical examination and liver function tests. Simultaneously the worm movement in the biliary system are monitored by serial abdominal sonograms. The success of conservative treatment in patients with biliary ascariasis and cholangitis is judged by subsidence of fever, pain, jaundice, and the disappearance of worms from the duct. The symptoms usually subside within three days, and it is always advisable to delay the administration of vermifuge until the acute symptoms have resolved; this approach prevents death of worms within the biliary tree (15). A dead worm cannot be expected to move out of the biliary tract into the duodenum, and a fragmented dead worm can also act as a nidus for stone formation (8). B-glucoronidase produced by ascarids hydrolyses with soluble bilirubin diglucoronide to form insoluble free bilirubin, which precipitates as calcium bilirubinate; thus initiating intrahepatic and extrahepatic lithiasis (15). The vermifuge of choice for roundworm infestation is pyrantel pamoate; mebendazole and albendazole are good alternative drugs (16). Spontaneous exit of worms from the bile ducts may be monitored by serial ultrasonography. Worm reinvasion of the biliary tree, frequently seen in endemic areas, may be prevented by prescribing antihelminthic treatment at regular intervals, thereby keeping the intestine free of worms (15).

Endoscopic extraction is indicated in patients who do not respond to conservative management, in whom the worms persist in the biliary ducts for 3 weeks and are likely to be dead and thus unable to migrate out of the biliary tree (15). Endoscopic extraction of worms across the papilla leads to rapid relief of symptoms (1). In experienced hands, endoscopic worm extraction from the ampullary orifice is successful in more than $90 \%$ of patients (3). But the use of ERCP must be balanced against potential complications of the procedure, as sphincterotomy performed during ERCP for worm extraction predisposes to recurrent worm infestation. (17).

Surgery continues to have a place in the management of biliary ascariasis, the main indications being endoscopic treatment failures; involvement of intrahepatic ducts by ascarids, leading to biliary stones, strictures and liver abscesses; presence of gallbladder ascariasis and rarely acute pancreatitis (15). Surgical treatment consists of cholecystectomy, removal of calculi and worms from biliary ducts and rarely from pancreatic duct (18) and drainage of liver abscess. Drainage procedures like T-tube drainage, choledochoduodenostomy, hepaticojejunostomy or even pancreaticojejunostomy may have to be resorted in different situations (15). In cases where repeated explorations have been performed for biliary ascariasis, an access loop hepaticocutaneous jejunostomy may be needed for dealing with recurrent lithiasis (19).

\section{Conclusion:}

Biliary ascariasis is common in high endemic areas of intestinal helminthiasis. Most cases respond to conservative management. In cases not responding to conservative management, ERCP can be used to remove the worm live or dead from bile ducts or pancreatic duct. Surgery can be used in patients not responding to conservative management or where ERCP facility is not available. Reninvasion of biliary tree may occur again and so regular deworming of patients to be done. 


\section{References:}

[1]. Khuroo MS, Zargar SA, Mahajan R. Hepatobiliary and pancreatic ascariasis in India. Lancet 1990; 335:1503-1506.

[2]. Pawlowski ZS. Ascariasis. In Warren KS, Mahmoud AAF, et al editors. Tropical and Geographical Medicine, $2^{\text {nd }}$ edition, New York, McGraw- Hill, 1990;369-378.

[3]. Khuroo MS. Ascariasis. Gastroenterol Clin North Am 1996;25:553-577.

[4]. Sandouk F, Haffar S, Zada MM, Graham DY, Anand BS. Pancreatic-biliary ascariasis: experience of 300 cases. Am J Gastrenterol 1997;92:2264-2267

[5]. Shah OJ, Dar MA, Wani NA, et al. Postoperative biliary ascariasis: presentation and management experience. World J Surg 2000;24:1143-1145

[6]. Khuroo MS, Zargar SA, Yattoo GN, et al. Sonographic findings in gall bladder ascariasis. J Clin Ultrasound 1992; 20:587-589.

[7]. Louw JH. Biliary ascariasis in childhood. S Afr J Surg 1974; 12: 19-25.

[8]. Khuroo MS, Zargar SA. Biliary ascariasis: a common cause of biliary and pancreatic disease in endemic area. Gastroenterology 1985;88: 418-423.

[9]. Yang SCH, Laube PL. Biliary ascariasis: report of 19 cases. Ann Surg 1946; 123:299-303.

[10]. Wright RM, Dorrough RL, Ditmore HB. Ascariasis of the biliary system. Arch Srg 1963;86:402-406.

[11]. Chang CC, Han CT. Biliary ascariasis in childhood. A clinical analysis of 788 cases. Clin Med J 1966; 85:167.

[12]. Schulaman A, Loxton AJ, Hegdenrych JJ, Abdulrahaman KE. Sonographic diagnosis of biliary ascariasis. AJR Am J Roentgenol $1982 ; 139: 485-489$

[13]. Cerri GG, Leite GJ, Simoes JB, Correia Da Rocha DJ, Albuquerque FP, Machado MC, et al. Ultrasonographic evaluation of Ascaris in the biliary tract. Radiology 1983; 146:753-754.

[14]. Lloyd DA. Massive hepatobiliary ascariasisin childhood. Br J Surg 1981;68: 468-473.

[15]. Omar Javed Shah, Showkat Ali Zargar, Irfan Robbani. Biliary ascariasis: a review. World J Surg 2006; 30:1500-1506.

[16]. Webster LT. Drugs used in the chemotherapy of helminthiasis. In: Gilman AG, Goodman LS, Rall TW, Murad F, editors. Goodman and Gilman's: The pharmacological Basis of Therapeutics, New York, Macmillan, 1985;1009-1028.

[17]. Madhumita Mukhopadhyay. Biliary ascariasis in the Indian Subcontinent: a study of 42 cases. The Saudi Journal of Gastroenterology 2009; 15(2): 121-124

[18]. Beckingham IJ, Cullis SNR, Krige JEJ, et al. Management of hepatobiliary and pancreatic ascaris infestation in adults after failed medical treatment. Br J Surg 1998;85:907-910

[19]. Krige JEJ, Bornman PC, Harries Jones EP, et al. Modified hepaticojejunostomy for permanent biliary access. Br J Surg 1987;74: 612-613 